\title{
Population niche breadth and individual trophic specialisation of fish along a climate-productivity gradient
}

\author{
Javier Sánchez-Hernández (i) - Brian Hayden (ㄱ) - Chris Harrod (1) • \\ Kimmo K. Kahilainen $(\mathbb{D})$
}

Received: 16 June 2021/Accepted: 25 September 2021 / Published online: 13 October 2021

(C) The Author(s) 2021

\begin{abstract}
A mechanistic understanding of how environmental change affects trophic ecology of fish at the individual and population level remains elusive. To address this, we conducted a space-for-time approach incorporating environmental gradients (temperature, precipitation and nutrients), lake morphometry (visibility, depth and area), fish communities (richness, competition and predation), prey availability (richness and density) and feeding (population niche breadth and individual trophic specialisation) for 15 native fish taxa belonging to different thermal guilds from 35 subarctic lakes along a marked climateproductivity gradient corresponding to future climate change predictions. We revealed significant and
\end{abstract}

Supplementary Information The online version contains supplementary material available at https://doi.org/10.1007/ s11160-021-09687-3.

J. Sánchez-Hernández ( $ه)$

Área de Biodiversidad y Conservación, Departamento de Biología y Geología, Física y Química Inorgánica,

Universidad Rey Juan Carlos, Móstoles,

Madrid, Spain

e-mail: javier.sanchezh@urjc.es

B. Hayden

Department of Biology, Canadian Rivers Institute,

University of New Brunswick, New Brunswick, Canada

C. Harrod

Instituto de Ciencias Naturales Alexander von Humboldt, Universidad de Antofagasta, Antofagasta, Chile contrasting responses from two generalist species that are abundant and widely distributed in the region. The cold-water adapted European whitefish (Coregonus lavaretus) reduced individual specialisation in warmer and more productive lakes. Conversely, the cool-water adapted Eurasian perch (Perca fluviatilis) showed increased levels of individual specialism along climate-productivity gradient. Although whitefish and perch differed in the way they consumed prey along the climate-productivity gradient, they both switched from consumption of zooplankton in cooler, less productive lakes, to macrozoobenthos in warmer, more productive lakes. Species with specialist benthic or pelagic feeding did not show significant changes in trophic ecology along the gradient. We conclude that generalist consumers, such as warmer adapted perch,

\author{
C. Harrod \\ Instituto de Antofagasta, Universidad de Antofagasta \\ Stable Isotope Facility, Universidad de Antofagasta, \\ Antofagasta, Chile \\ C. Harrod \\ Núcleo Milenio INVASAL, Concepción, Chile \\ K. K. Kahilainen \\ Lammi Biological Station, University of Helsinki, \\ Lammi, Finland \\ K. K. Kahilainen \\ Kilpisjärvi Biological Station, University of Helsinki, \\ Kilpisjärvi, Finland
}


have clear advantages over colder and clear-water specialised species or morphs through their capacity to undergo reciprocal benthic-pelagic switches in feeding associated with environmental change. The capacity to show trophic flexibility in warmer and more productive lakes is likely a key trait for species dominance in future communities of high latitudes under climate change.

Keywords Environmental change $\cdot$ Fish . Multichannel feeding - Stomach content analysis . Thermal guild $\cdot$ Subarctic lakes

\section{Introduction}

Global change has led to local environmental shifts that, in turn, trigger detrimental effects on both communities and ecosystem functioning across biomes (e.g. Garcia-Palacios et al. 2015; Till et al. 2019; Pecuchet et al. 2020). In temperate aquatic biomes, global climate change is leading to an increase in water temperature and productivity (Finstad et al. 2016; Hayden et al. 2019; Kritzberg et al. 2020). As a consequence, northern lentic systems are undergoing greening and an associated shift in fish communities from a dominance of cold-adapted, clear water fishes to communities dominated by warm- and murky water adapted species (Hayden et al. 2017; Jacobson et al. 2017). In addition, changes in thermal and productivity status have direct consequences for pelagic productivity, increasing abundance in phytoplankton and zooplankton, and thus a shift from communities dominated by benthic species, to ones dominated by pelagic fishes (de Senerpont Domis et al. 2013; Hayden et al. 2019).

Different species and life stages of fish are commonly assigned to thermal guilds, i.e. cold-, cooland warm-water species, according to their specific optimal and tolerance temperatures (Magnuson et al. 1979; Matthews and Maness 1979; Beitinger et al. 2000). The thermal guild of fish is an important determinant of optimal performance, with fish competing for preferred thermal niches (Magnuson et al. 1979). In northern latitudes, climate warming is predicted to give an advantage to cool-adapted and warm-adapted freshwater fishes (e.g. most cyprinids) over cold-adapted species (e.g. salmonids) (e.g.
Daufresne et al. 2003; Matulla et al. 2007; Graham and Harrod 2009) in line with species-specific optimal and tolerance ranges (Matthews and Maness 1979; Beitinger et al. 2000). Thus, new environmental conditions driven by climate-change are detrimental for cold-stenothermal fish species, in particular in shallow lakes, in comparison with warm-eurythermal fish species characterised by a high heat tolerance and an ability to cope with, or even thrive under, these new thermal regimes (Jeppesen et al. 2012). Moreover, a species designation to a specific thermal guild is strongly influenced by oxygen requirements, i.e. aerobic scope that may have additional importance in optimal performance and niche selection (Jacobson et al. 2010; Whitney et al. 2016). Thus, it is reasonable to expect distinct functional responses of fish to new oxythermal conditions, which will largely determine their performance following environmental shifts.

Knowledge has rapidly advanced regarding the poleward expansion of generalist and warm-adapted species in both freshwater and marine systems (e.g. Moss et al. 2009; Rolls et al. 2017; Pecuchet et al. 2020). However, there is still much to understand regarding how fish species can adapt their feeding and establish through this poleward expansion. In this regard, the intuitive pathway explaining the fishes' feeding shifts along environmental change is that new environmental conditions are expected to drive changes in prey communities which, in turn, lead changes in fish feeding and niche variation via bottomup mechanisms (Sánchez-Hernández et al. 2019a). More precisely, climate-induced modifications will lead to increased biomass of phytoplankton and zooplankton in northern and oligotrophic lakes (de Senerpont Domis et al. 2013). However, the effects can be taxon-specific on the metazooplankton communities of large and deep alpine lakes, with cladocerans increasing, and copepods decreasing or showing no variation (Hampton et al. 2008; Tanentzap et al. 2020). Aquatic insect communities are expected to become more homogeneous under global warming (Li et al. 2014), with the distribution and abundance patterns of some aquatic insects (Ephemeroptera, Diptera, Trichoptera and Plecoptera) being negatively affected (Li et al. 2014; Bhowmik and Schäfer 2015). In addition, climate-driven changes likely impact the size of ectothermic aquatic organisms (both prey and fish), with global warming in aquatic systems increasing the proportion of small-sized species and young 
age classes (Daufresne et al. 2009). It is reasonable to posit that flexible behavioural feeding responses of consumers may provide them with key advantages against future climate-driven changes in prey community structure, as trophic generalists are capable to adapt their diet to available food, whereas trophic specialists typically depend on a particular prey (Rijnsdorp et al. 2009).

Trophic specialists can function as ecological generalists when food resources are abundant and easy to capture (Liem 1980; Robinson and Wilson 1998). Thus, the capacity of consumers to switch diet is likely to provide them with a competitive advantage following rapid global change (Bartley et al. 2018), but researchers still need to integrate the potential of consumers displaying trophic switches such as multichannel feeding, i.e. coupling horizontal (littoralpelagic axis) and vertical (profundal/benthic-pelagic axis) components of lake food webs, when assessing the response of consumers to environmental scenarios driven by global change (Duffy et al. 2007; Wolkovich et al. 2014). In this regard, lacustrine species with generalist feeding behaviours, such as omnivores, are expected to enhance multichannel feeding that link autotroph-based pelagic and detritus-based benthic compartments of lake food webs (Wolkovich et al. 2014). For example, a common pattern among generalist fish, such as Eurasian perch Perca fluviatilis, is a switch in foraging along the littoral-pelagic axis during ontogeny (i.e. from pelagic zooplankton to benthic invertebrate and latter to pelagic fishes) (Persson 1986; 1990; Sánchez-Hernández et al. 2019b). This capacity to switch diet is likely to provide them with a competitive advantage following rapid changes to their environment. Indeed, poleward expansion of fish generalists has led to marked functional shifts, e.g. through increased benthicpelagic coupling and enhanced connectivity between habitats, and thus the structure of marine food-webs (Kortsch et al. 2015). Empirical work has also emphasised the ecological significance of fish generalists as promoters of stability in fish communities under current climate change via trophic niche segregation (Kingsbury et al. 2020). In addition, the most important factors besides temperature, productivity and associated environmental variables driving feeding responses of consumers at both population and individual levels are related to resource availability and competition (Schluter 2000; Araújo et al. 2011; Skúlason et al. 2019; Sánchez-Hernández et al. 2021).

In the current study, we used fish as model organisms and integrated both biological processes (competitor and predator abundance and prey availability) and environmental components (warming, increased productivity and lake morphometry) by using a real world, space-for-time gradient from rapidly changing subarctic lake ecosystems. In this regard, high-latitude regions are one of the fastest warming areas of the world due to the phenomenon of Arctic amplification (Coumou et al. 2018). Specifically, we examined among-individual (measured as individual trophic specialisation) and population (population niche breadth) diet variation in native fish species and whitefish morphs (Coregonus lavaretus) from subarctic lakes along a pronounced climateproductivity gradient (i.e. along warmer and more productive lakes). Trophically polymorphic fish, such as the European whitefish morphs inhabiting large parts of northern Fennoscandia, can be used as model organisms to study differences in trophic specialization beyond the species level across the three major habitats of lentic systems (littoral, pelagic and profundal) (Harrod et al. 2010; Præbel et al. 2013; Thomas et al. 2017) as well as their responses to climate-productivity gradient. We hypothesised (H1) that climate-productivity gradients drive changes in trophic niche of predators based on their thermal guild, expecting both population niche breadth and individual trophic specialisation to decrease in cold and clear water fish species (i.e. whitefish and vendace Coregonus albula) as lakes became warmer and more productive, with the pattern reversed in cool and warm water fish species (i.e. Eurasian perch and ruffe Gymnocephalus cernua). We predict that multichannel feeding capacities, i.e. reciprocal benthic-pelagic switches in feeding of omnivorous or generalist fish, associated with changes in pelagic productivity may act as a key trait to understand feeding responses to climate change at both the individual and population levels. In turn, we also hypothesised (H2) that this pattern would be continued, where specialised trophic morphs of whitefish would differ from that of the most widely distributed generalist morph (Harrod et al. 2010). 


\section{Material and methods}

Study area

We sampled 35 lakes in Finnish Lapland in August or September between 1998 and 2014 (Appendix 1). The sampling program included measurements of climate [open-water season air temperature $\left({ }^{\circ} \mathrm{C}\right)$ and precipitation $(\mathrm{mm})$ ], productivity [total nitrogen $(\mu \mathrm{g} / \mathrm{L})$ and total phosphorus $(\mu \mathrm{g} / \mathrm{L})$ ], lake morphometry [compensation depth $(\mathrm{m})$, maximum depth $(\mathrm{m})$, mean depth (m), littoral proportion (\% of lake surface area) and lake area $\left(\mathrm{km}^{2}\right)$ ], prey availability (richness and density of zooplankton (n/L) and macrozoobenthos $\left(\mathrm{n} / \mathrm{m}^{2}\right)$ - putative prey for much of the fish community) and key characteristics of the fish community (fish richness, inter- and intra-specific competition and predation risk). This allowed us to conduct a spacefor-time analysis across a temperature-productivity gradient equivalent to the future climatic shift predicted for subarctic Europe (i.e. temperature $+3{ }^{\circ} \mathrm{C}$, precipitation $+30 \%$ and nutrient $+45 \mu \mathrm{g} \mathrm{L}^{-1}$ total phosphorus; for details see Hayden et al. 2019). These environmental differences are derived from altitudinal and strong catchment land-use gradients which result in the close to pristine northernmost lakes being the coldest and least productive, and the most southern lakes being warmer and notably more productive.

Environmental gradients: climate-productivity index $\left(\mathrm{CP}_{\mathrm{i}}\right)$ and lake morphometry index $\left(\mathrm{M}_{\mathrm{i}}\right)$

Using previously described methods (Hayden et al. 2019), Principal Component Analysis (PCA) was used to combine variation in temperature, precipitation, total nitrogen and total phosphorus to a single composite variable (the climate-productivity index; hereafter $C P_{i}$ ) which explained $81 \%$ of observed environmental variation among lakes (Appendix 2). Our rationale is that PCA scores capture variation in environmental conditions, reducing environmental information to a single variable that was later used as an indicator of environmental status. Following the same procedure as for $C P_{i}$, PCA was used to reduce information on lake morphometry to one dependent variable, which explained $54.6 \%$ of such environmental variation (Appendix 2) and was then used as an indicator of lake morphometry.
Fish communities and sampling

Lakes (mean area $=8 \mathrm{~km}^{2}$ and mean depth $=6 \mathrm{~m}$ ) largely supported multi-species fish communities (mean number of species $=8$ ) that included both invertivorous and piscivorous fish species. All fish species are native to Finland, except peled whitefish (Coregonus peled) and lake trout (Salvelinus namaycush) which have been stocked in two of the study lakes (Table 1A in Appendix 1). Both these species are rare and are not included in subsequent analyses. Not all lakes contained the same fish community (Table 1A in Appendix 1). Invertivorous fish species included a wide variety of feeding guilds including (1) obligate planktivores (vendace and bleak Alburnus alburnus), (2) obligate benthivores (burbot Lota lota, ruffe and grayling Thymallus thymallus). Generalist fish species included species which feed on both zooplankton and zoobenthos (whitefish, including four morphs, and roach Rutilus rutilus) as well as fish prey (perch) (Hayden et al. 2017, 2019). Whitefish morphs occur in eight lakes, with each lake supporting two to four morphs per lake (Thomas et al. 2017; Häkli et al. 2018). Four lakes contain whitefish $\times$ vendace hybrids (Kahilainen et al. 2011). Piscivorous fish species in these subarctic lakes included brown trout (Salmo trutta), Arctic charr (Salvelinus alpinus) and pike (Esox lucius) (Thomas et al. 2017; Hayden et al. 2019). Cold-water fish species include whitefish (all morphs), vendace, whitefish $\times$ vendace hybrids, brown trout, Arctic charr, grayling and burbot. Perch, ruffe, pike are classified as cool-water fish species, and roach and bleak are classified as warm-water fish species. The most common species across the temperature-productivity gradient were whitefish, vendace, perch and ruffe (Table 1). Polymorphic fish populations are most commonly seen in whitefish, but across a larger (European) scale morphs or subspecies are also known for the remaining three species (Kottelat and Freyhof 2007; Skúlason et al. 2019). All fish species, morphs and hybrids studied here are particulate feeding species.

Fish were sampled from littoral, pelagic and profundal zones using multimesh (5-75 mm knot to knot) gill nets fished overnight (Hayden et al. 2014, 2017, 2019). Fish were collected the following morning (soak time c. $6-12 \mathrm{~h}$, recorded $\pm 1 \mathrm{~min}$ ), immediately killed with cerebral conclusion and chilled in ice. All fish were identified in the laboratory 


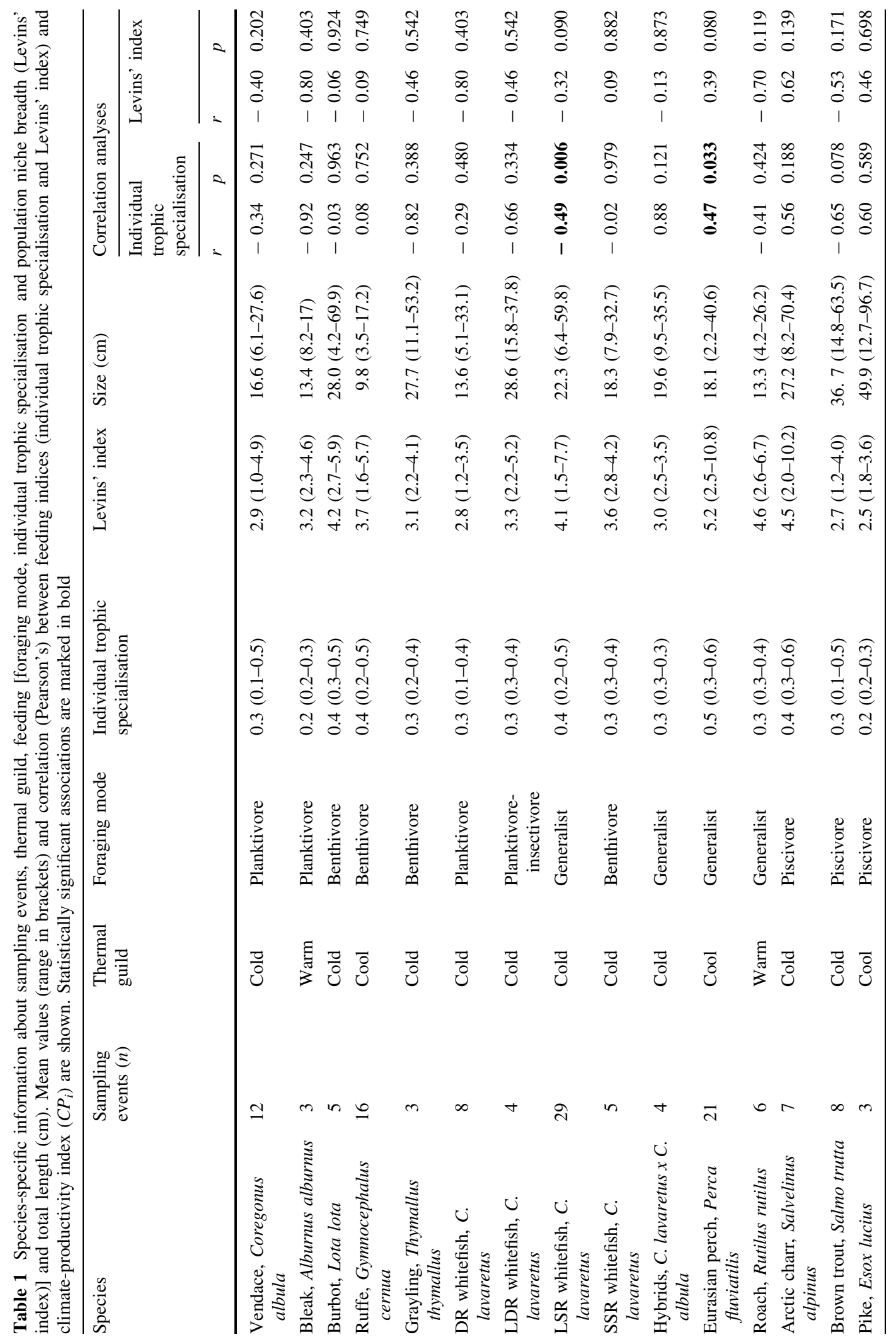


to species, morph or hybrid level (Tables $1 \mathrm{~A}$ and $3 \mathrm{~A}$ in Appendices 1 and 3, respectively). Regarding whitefish morphs, the dataset included eight lakes inhabited by 2-4 sympatric whitefish morphs and 21 monomorphic lakes inhabited by a single whitefish morphlarge sparsely rakered (LSR) (Appendix 3). Whitefish morphs were identified according to their differences in body, head and gill raker morphology (Harrod et al. 2010; Kahilainen et al. 2014).

All fish sampled were counted, measured (total length, $\pm 1 \mathrm{~mm})$ and frozen $\left(-20^{\circ} \mathrm{C}\right)$ for further analysis. The relative abundance of different fish taxa in each lake was estimated as Catch Per Unit Effort (CPUE individuals net series ${ }^{-1} \mathrm{~h}^{-1}$ ). Population and individual level diet of fish is highly dependent on trophic resource competition and prey availability (Araújo et al. 2011; Sánchez-Hernández et al. 2021). We therefore used total and species-specific CPUE as a proxy for potential inter- and intra-specific competition, respectively, with the assumption that high CPUE equates to high fish abundance and increased potential competition for food resources (Svanbäck and Persson 2004; Sánchez-Hernández et al. 2017a). In addition, we calculated fish species richness and the invertivorous CPUE/piscivorous fish CPUE ratio as a proxy of fish community structure and predation risk (e.g. Mehner et al. 2016), respectively.

Prey availability: zooplankton

and macrozoobenthos densities and diversity

The current study focussed on prey resource abundance and diversity in the three lake habitats: pelagic (zooplankton), littoral (littoral macrozoobenthos) and profundal (profundal macrozoobenthos). The protocol for our sampling to characterise prey availability is described in detail in Hayden et al. (2017). Briefly, pelagic zooplankton were sampled in triplicate with vertical hauls of a zooplankton net $(25 \mathrm{~cm}$ diameter, $50 \mu \mathrm{m}$ mesh size) at the deepest point in each lake or from the principal research area in the case of very large lakes and immediately fixed in a 5\% formalin solution. Crustacean zooplankton (copepods and cladocerans) were identified and counted $\left(\mathrm{n} \mathrm{L}^{-1}\right)$ under a dissection microscope. Three replicate samples of macrozoobenthos were collected from littoral and profundal areas using an Ekman grab $\left(272 \mathrm{~cm}^{2}\right)$, sieved (500 $\mu \mathrm{m}$ mesh size) stored in plastic buckets. Some lakes lacked profundal habitats (Kelotti, Kolta,
Palo, Peera, Siilas, Tuulis and Vaggoval) as light penetrates to the lake bottom even at their deepest points, due either to limited maximum depth or very clear water, and thus no differentiation between profundal and littoral macrozoobenthos communities was made in these lakes. Samples were transported to a field laboratory, identified (mostly to family level for macrozoobenthos and genus level for zooplankton; Appendix 4), sorted and counted $\left(\mathrm{n} / \mathrm{m}^{2}\right)$. Prey diversity was calculated as taxa richness (i.e. number of invertebrate taxa) in the pelagic, littoral and profundal habitats.

We identified the most abundant prey categories in each lake habitat (Appendix 4) in order to explore the importance of the absolute abundance of the dominant prey categories on population and among-individual diet variation (Sánchez-Hernández et al. 2021) along $C P_{i}$. In the pelagic habitat, Bosmina spp., Copepoda (both Calanoida and Cyclopoida), Chydorus spp. and Daphnia spp. were the most common taxa. Regarding the macrozoobenthos community, Chironomidae, Asellus spp., Eurycercus spp. and Oligochaeta were the most represented taxa in the littoral; whereas Chironomidae, Oligochaeta and Pisidium spp. dominated the profundal assemblage (Fig. 4A in Appendix 4). Despite the relative abundance of Oligochaeta, this taxon was not considered as a predictor in further modelling because it was not found in the stomach contents of any fish (Fig. 4B in Appendix 4). Thus, this study covered absolute abundance of those taxa and total prey density.

Stomach contents analysis: individual trophic specialisation and population niche breadth

Because the digestive systems of carnivore, omnivore and planktivore fish species are different (Gerking 1994), we analysed the anterior third of gastrointestinal tracts of cyprinids (roach, bleak and minnow) and stomach contents of carnivore fish (stomach contents from here onwards) according to previous studies (e.g. Encina et al. 2004; Sánchez-Hernández et al. 2011). In total, we analysed $>21,000$ individual fish, following standardised procedures for stomach content analysis (Amundsen and Sánchez-Hernández 2019) to maximise data quality. Dietary analysis was restricted to populations for which a minimum of 15 individuals per species were sampled. Stomach contents were identified to the lowest feasible taxonomic 
level (usually the same taxonomic level as for zooplankton and macrozoobenthos) and the relative abundance of each prey to the total stomach fullness was determined using the points method (ranking stomach fullness from 0 to 10 , where 0 denotes an empty stomach and 10 a stomach at maximal extension; Hynes 1950; Amundsen and Sánchez-Hernández 2019). In the case of cyprinid species (omnivorous feeding strategy) which do not have a defined stomach, we only examined contents from the anterior third of the intestine and used a percentage scale for fish having ingested prey i.e. 100\% visually divided into different categories. Empty intestines were scored as zero. For the full data, we first discarded individuals with stomach fullness scores lower than three ( $n=8101)$ to avoid bias resulting from possible inflation in the estimation by individuals feeding on few prey items or indigestible remains that can be retained in the stomach for prolonged periods of several weeks (Amundsen and Sánchez-Hernández 2019). Individuals were then grouped by species or morph per lake and dietary analysis conducted only where a minimum threshold of individuals $(n \geq 15)$ per species or morph and lake was met. This led to another 1015 individuals being discarded. The final quality- and quantity-screened dataset included a total of 11,918 individuals, 134 sampling events (i.e. individual populations as multiple samples from different years aggregated per lake) within 15 species, morphs and hybrids (Table 1) in a total of 35 lakes spanning $67^{\circ} \mathrm{N}$ to $70^{\circ} \mathrm{N}$.

To study individual trophic specialisation of fish species at mean population levels (i.e. using the mean value of all individuals for each sampling lake), the proportional similarity $\left(P S_{i}\right)$ index was calculated (Bolnick et al. 2002). This index compares each individual's diet to that of the population, with values ranging between 0 and 1 . For individuals that specialise on a single or few prey types, $P S_{i}$ values are low, whereas for individuals that consume resources in a similar proportion to the population as a whole, $P S_{i}$ values approach 1 (Bolnick et al. 2002). However, we used the inverse of the average similarity index (1-IS; Quevedo et al. 2009), to estimate the overall prevalence of individual specialisation in each population for a more intuitive interpretation (meaning that trophic specialisation is high when values approach 1). Because among-individual differences in resource specialisation may drive broader population- level trophic niches via individual niche diversification in fish (Sánchez-Hernández et al. 2021), we also addressed the trophic niche breadth at the population level through Levins' D index (Levins 1968) using the same dietary categories across lakes (Appendix 4).

\section{Statistics}

All analyses and visualisation were carried out using R version 3.6.2 (R Core Team 2019). The proportional similarity $\left(P S_{i}\right)$ and Levins' $D$ indices were calculated using the RInSp package version 1.2.3 (Zaccarelli et al. 2013). Shapiro-Wilk $(\mathrm{n}<50)$ and KolmogorovSmirnov $(n>50)$ tests indicated non-normality in the data.

Prior to analyses, variance inflation factors (VIF) were used to detect multicollinearity between total prey density and absolute abundance of the most represented prey categories for each lake habitat (littoral, pelagic and profundal). Zuur et al. (2010) recommend $\mathrm{VIF}<3$ as an indicator of low evidence for collinearity. Accordingly, no indication of multicollinearity was found (values between 1.04 and 2.80). In a first attempt to test for simple cause-and-effect associations between i) biota richness and abundance (zooplankton, macrozoobenthos and fish) and the climate-productivity gradient (climate-productivity index $\left.-C P_{i}\right)$, and ii) feeding $\left(P S_{i}\right.$ and $\left.D\right)$ of fish species and whitefish morphs and predictors (environmental status, zooplankton, macrozoobenthos and fish variables), we used Pearson's rank correlations with threshold levels adjusted by Bonferroni correction, in which the $p$-values are multiplied by the number of comparisons. Pairwise comparisons between monoand polymorphic whitefish were tested through nonparametric Mann-Whitney-Wilcoxon test to explore the hypothesis $(\mathrm{H} 2)$ that specialised trophic morphs of whitefish would differ from the most widely distributed generalist morph.

Because our data did not meet normality and hence the assumptions for linear regression models (Zuur et al. 2009), we used multiple regression with Generalised Additive Models (GAMs) ("mgcv" package version 1.8.28; Wood 2017) to uncover the main drivers in fish feeding responses at individual (individual trophic specialisation) and population (population niche breadth) levels along $C P_{i}$. Considering that models cannot be carried out having more predictor variables than number of observations, we started out 
with a full model incorporating a maximum number of 13 predictor variables with significant impact on individual trophic specialisation and population niche breadth (Appendix 5): $C P_{i}$, lake morphometry index $\left(M_{i}\right)$, prey availability (zooplankton richness, Bosmina density, Daphnia density, Cyclopoida density, total zooplankton density, Eurycercus density, profundal Chironomidae density and total profundal macrozoobenthos density), total CPUE (as a proxy of interspecific resource competition), predation risk and fish richness with $C P_{i}$ as a smoothed variable. In the case of vendace, the number of observations imposed a limitation in the number of variables to be included in the full model and consisted of eight predictor variables $\left(C P_{i}, M_{i}\right.$, zooplankton richness, Bosmina density, Daphnia density, total CPUE and predation risk) with $C P_{i}$ as a smoothed variable.

We used $\triangle$ AIC based model selection (Burnham and Anderson 2002) to select the optimal model structure and rank candidate models using the MuMIn package version 1.40.0 (Bartoń 2016). Because models with $\triangle \mathrm{AIC}$ values $<2$ relative to the best model are considered to have substantial support (Burnham and Anderson 2002), we explored relative importance using model averaging (MuMIn package). It should be noted that multiple regression analyses were only carried out for a subset of species (perch, ruffe, vendace and LSR whitefish) with a representative number of sampled lakes ( $n>10$ lakes, range: $12-33)$ to avoid overfitting of models. We visually inspected residuals of the final selected models for deviations from normality and heteroscedasticity, without finding evidence of violation of the model assumptions (Appendix 6). Following the same above-mentioned criteria ( $n>10$ lakes), the comparison of diet composition in whitefish trophic polymorphisms between monomorphic and polymorphic lakes was only carried out for LSR whitefish. A significance level of $p=0.05$ was used for all analyses.

\section{Results}

Zooplankton density (Pearson correlation: $r=0.43$; $p<0.001), \quad$ zooplankton richness $\quad(r=0.62$; $p<0.001)$, density of littoral macrozoobenthos $(r=0.50 ; p<0.001)$, density of profundal macrozoobenthos $(r=0.38 ; p<0.001)$ and CPUE total $(r=0.69 ; p<0.001)$ increased along the climate- productivity index $\left(C P_{i}\right)$. Conversely, macrozoobenthos richness in both littoral and profundal habitats did not show any clear association with $C P_{i}(r=0.09$; $p=0.260$ and $r=-0.01 ; p=0.973$, respectively).

Most fish species showed a negative correlation between individual trophic specialisation and $C P_{i}$ (Table 1). However, the correlation was only statistically significant in two species; LSR whitefish showed a negative $(r=-0.49 ; p=0.006)$ trend between individual trophic specialisation and $C P_{i}$, while perch showed a positive $(r=0.47 ; p=0.033)$ trend (Fig. 1). No statistically significant correlations between population niche breadth of fish species and $C P_{i}$ were found (Table 1). Individual trophic specialisation increased with Levins' index in all fish species (perch, ruffe, vendace and LSR whitefish) with a representative number of sampling events $(r=0.88$; $p<0.001, r=0.92 ; p<0.001, r=0.85 ; p<0.001$ and $r=0.89 ; p<0.001$, respectively), showing that individual trophic specialisation drove a concomitant rise in the trophic niche breadth of the population (Fig. 2).

Fish species appear to differ in prey consumption along the climate-productivity gradient in line with their feeding strategies, switching between zooplankton and macrozoobenthos consumption (Fig. 3). Notably, generalist LSR whitefish switched from pelagic to benthic foraging in warmer and more productive lakes, whereas the benthic-pelagic foraging switch was less evident in the remaining fish species (Fig. 3). We found differences in the diet composition of LSR whitefish from monomorphic and polymorphic lakes (Fig. 4), consumption of benthic prey was higher in polymorphic lakes (Mann-Whitney-Wilcoxon test; $W=966,699 ; p<0.001)$. Conversely, consumption of pelagic prey [zooplankton and surface prey (terrestrial arthropods and emerged aquatic insects)] by LSR whitefish was higher in monomorphic lakes $(W=1,221,694 ; p<0.001$ and $W=1,172,876 ; p<0.001$, respectively).

Simple cause-and-effect associations between fish feeding (individual trophic specialisation and population niche breadth) and prey abundance or total CPUE showed different species-level responses (Fig. 5 and Appendix 5). For example, both individual and population feeding responses of perch increased with perch abundance (CPUE), but an opposite pattern was seen in LSR whitefish. In addition, total CPUE rather species-specific CPUE and prey abundance rather than 


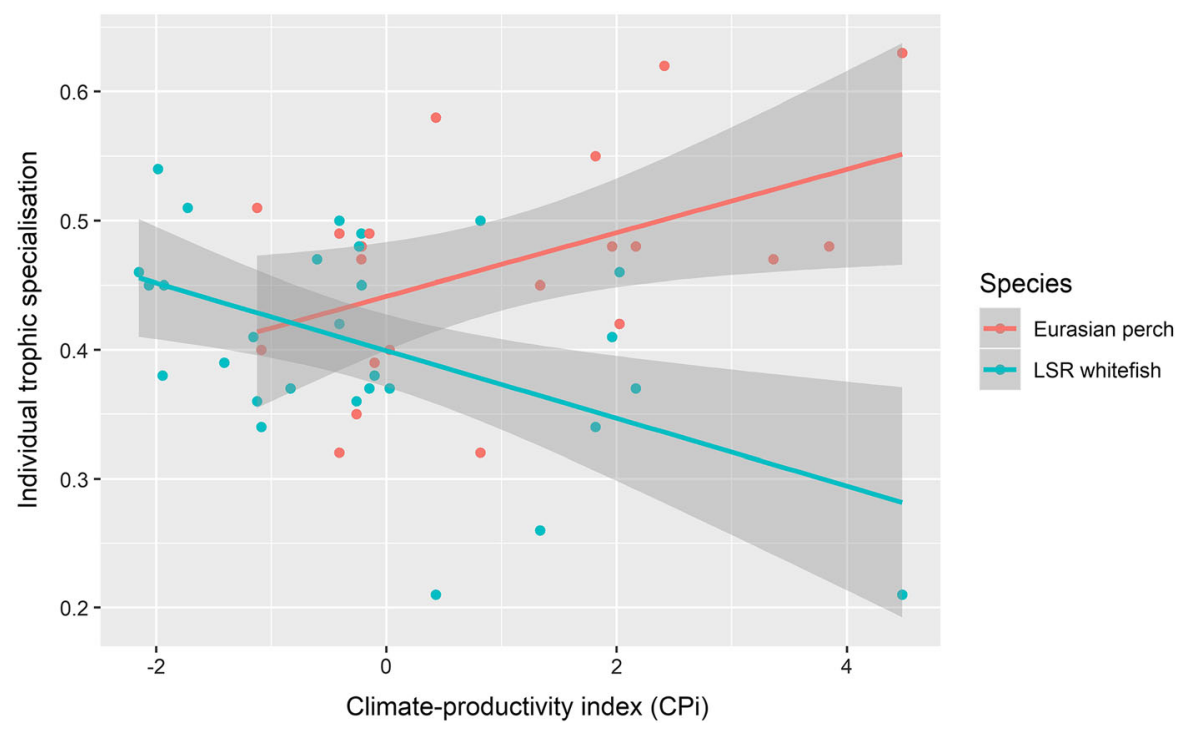

Fig. 1 Individual trophic specialisation along climate-productivity gradients $\left(C P_{i}\right)$ for two species showing statistically significant, but contrasting responses (see Table 1 for Pearson's

diversity had a stronger impact on individual and population niche variation of perch, ruffe and vendace; whereas individual and population diet in LSR whitefish were negatively associated with zooplankton diversity and densities of Daphnia spp. and Bosmina spp. (Appendix 5).

Multiple regression models supported the importance of $C P_{i}$, prey density and inter-specific competition in explaining individual trophic specialisation and population niche breadth of fish species, and indicated that prey diversity and lake morphometry index were less important (Tables 2 and 3). Overall, zooplankton was more important for planktivorous specialist vendace (Bosmina density for population niche breadth) and generalist perch (Cyclopoida density for both individual trophic specialisation and population niche breadth) than for the benthivorous ruffe, where individual and population feeding was dependent on macrozoobenthos (profundal Chironomidae density) (Table 2). Individual and population level diet of generalist LSR whitefish was dependent on interspecific competition (total CPUE) and fish community (fish richness) in combination with Bosmina density (individual trophic specialisation) and Eurycercus density (both individual trophic specialisation and population niche breadth) (Table 2). The best model configurations were robust (see explained deviance in Table 3), and confirmed the key rank correlations). Linear smoothers (shaded area denotes $95 \%$ confidence interval) are fitted to the data for illustrative purposes to show trends in individual trophic specialisation

importance of $C P_{i}$ (perch, vendace and LSR whitefish), zooplankton density (perch), profundal macrozoobenthos density (ruffe) and inter-specific competition (LSR whitefish) in explaining individual trophic specialisation and population niche breadth in our study (Table 3).

\section{Discussion}

We examined variation in individual trophic specialisation and population niche breadth in different freshwater fish guilds along a marked climate-productivity gradient that matches possible future climatic shifts in northern biomes. Our results provide novel insights into how warmer and more productive future climate scenarios in high latitudes are likely to provide an advantage to warmer adapted generalist fish species, such as perch, through their reciprocal capacity to switch between benthic and pelagic resources (multichannel feeding). Conversely, coldadapted fish species showed mostly a negative relationship between individual and population feeding and the climate-productivity index, most clearly shown in the generalist, cold-water adapted LSR whitefish. Thus, our first hypothesis predicting increases in individual trophic specialisation and population niche breadth along climate-productivity 


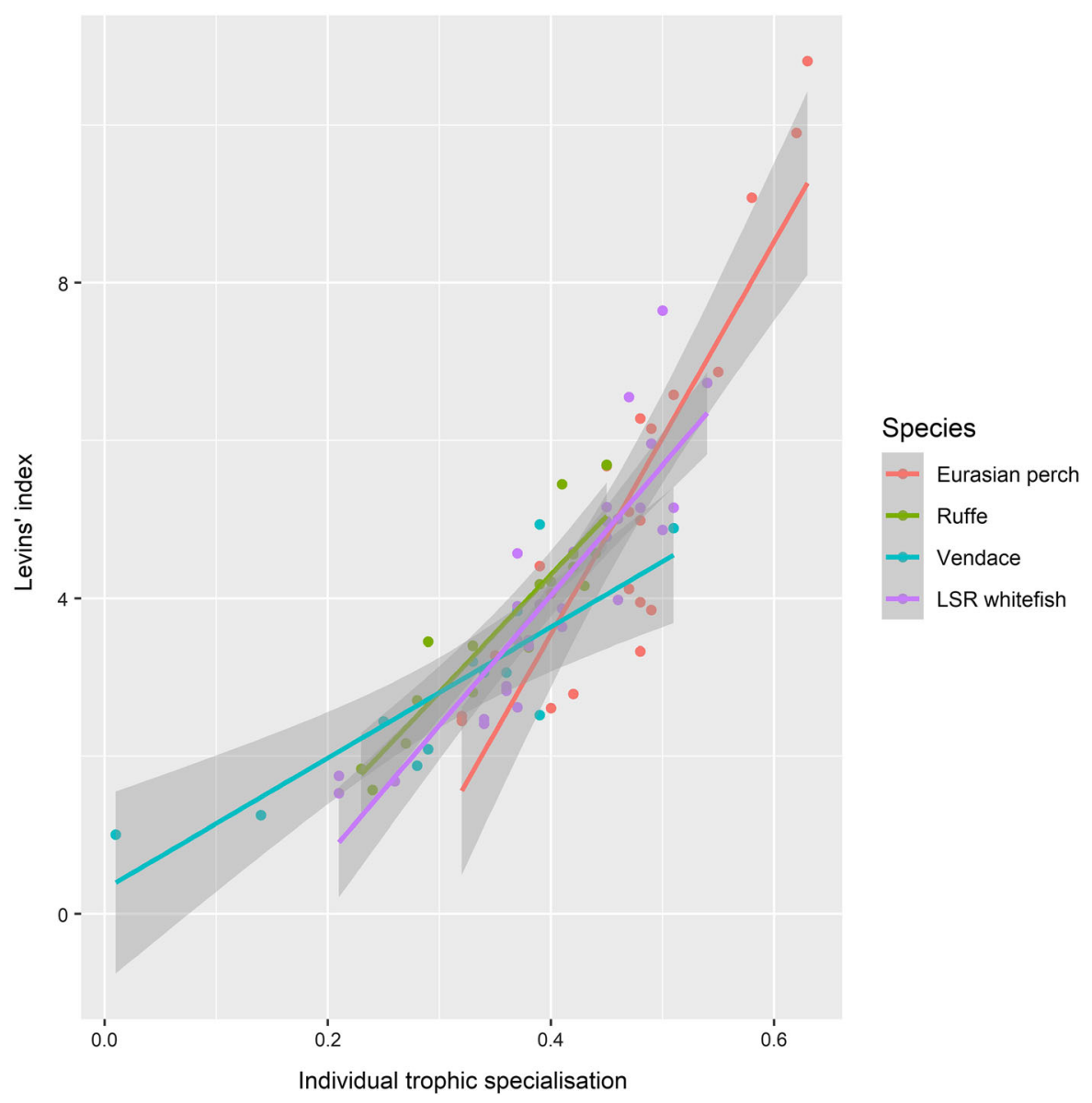

Fig. 2 Linkage between population diet variation (Levins' population niche breadth) and among-individual diet variation (individual trophic specialisation) in species (Eurasian perch, ruffe, vendace and LSR whitefish) with a representative number

gradients in cool- and warm-water fish species, but an opposite pattern in cold-water fish species, was partially supported because only a single cool-water and generalist fish species (perch) showed a clear positive trend between individual trophic specialisation and the climate-productivity gradient. Whitefish showed resource polymorphism in cold and clearwater lakes, but the trophic divergence displayed by specialised morphs disappeared towards warmer and productive conditions, supporting predictions from our second hypothesis regarding feeding responses to climate change in trophic morphs.

Perch and LSR whitefish were the most commonly captured fish species and present in the largest number of lakes, suggesting that our conclusions regarding these species are robust and can be extrapolated to taxa of sampling events. Linear smoothers (shaded area denotes 95\% confidence interval) are fitted to the data for illustrative purposes to show trends between variables

with similar biological requirements. We observed population niche expansion (i.e. Levins index) through individual trophic specialisation in fish species with a representative number of sampling events (perch, ruffe, vendace and LSR whitefish). This is in line with recent works focussed on stream fishes (SánchezHernández et al. 2021) and amphibians (Mirabasso et al. 2020). To the best of our knowledge, a mechanistic understanding of how climate change drives switches in fish population niche breadth and individual trophic specialisation is currently unavailable. A possible limitation of the current knowledge about the effect of climate change on niche breadth and individual trophic specialisation of fish species is related to the sampling efforts and duration of research programs as, for example, long-term studies constitute 


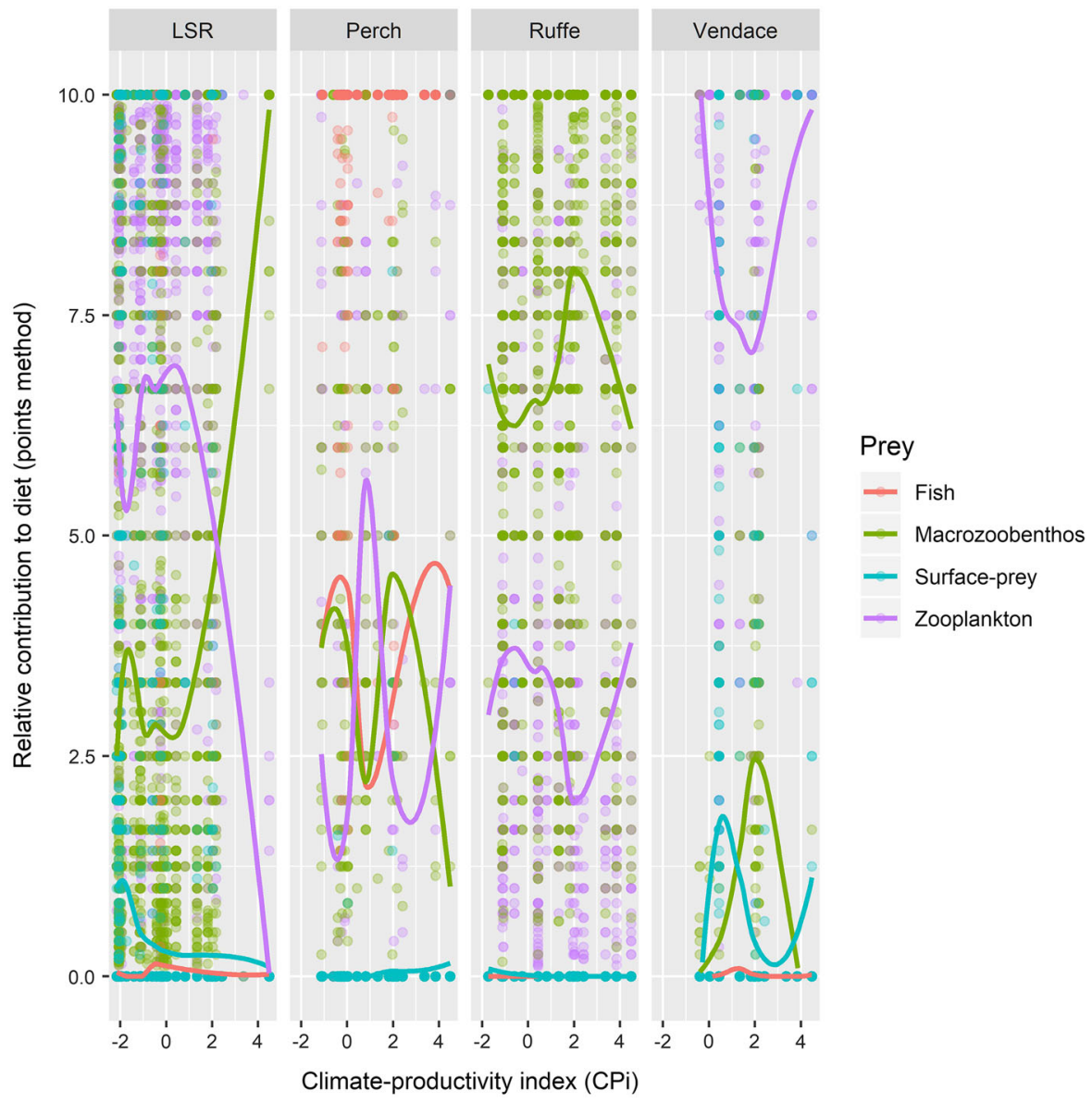

Fig. 3 Individual diet variation of selected fish species with a representative number of sampling events (see Material and Methods section) along climate-productivity gradients $\left(C P_{i}\right)$. Diet composition were grouped into four prey categories

a small fraction (5-6\%) of research efforts in aquatic systems (Xenopoulos 2019). However, a recent study of terrestrial vertebrates (generalist lizard predators) demonstrated that warmer climatic conditions resulted in higher degree of individual trophic specialisation for both adults and juveniles, whereas different patterns in respect to the population niche breadth (broader in warmer climatic conditions for juveniles, but narrower for adults) (Bestion et al. 2019).

The current study supports the view that, although more evident in individual trophic specialisation, population and individual diets are promoted by changes in prey availability and competitive scenarios along climate-productivity gradients. Several studies have demonstrated the poleward and altitudinal expansion of fish generalists and warm- and turbid (zooplankton, macrozoobenthos, surface prey and fish) for illustrative purposes. Surface prey included terrestrial arthropods and emerged aquatic insects

water adapted species as consequence of climate change (e.g. Moss et al. 2009; Comte and Grenouillet 2013; Rolls et al. 2017). However, our results highlight that generalist fish species can be expected to display distinct and opposite behavioural responses to novel conditions in warming subarctic lakes. For example, perch became more specialised with increasing temperature and productivity, whereas LSR whitefish switched to a more generalised feeding. Whitefish and perch compete for trophic resources in cold and resource-poor subarctic lakes, where coolwater adapted perch perform poorly and are restricted to littoral habitats. Conversely, cold-water adapted whitefish perform well and use all available habitats (Hayden et al. 2014). We provide evidence that fish generalists can act as resource channel switchers (i.e. 


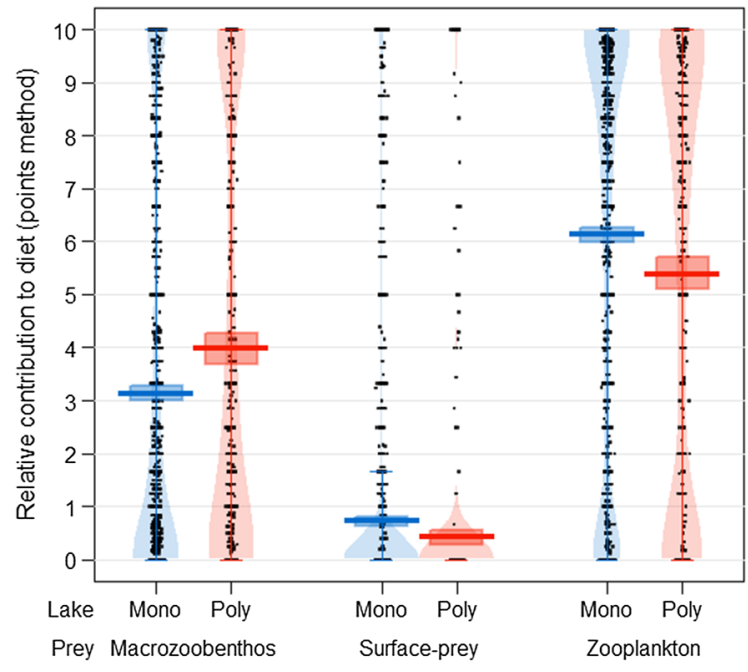

Fig. 4 Violin plots (box plots with probability density) showing relative contribution of different prey categories to the diet of LSR whitefish according to lake type $($ Mono $=$ monomorphic whitefish population, Poly $=$ polymorphic whitefish populations; points method which ranks stomach fullness from 0 to 10 , see Hynes 1950; Amundsen and Sánchez-Hernández, 2019 for further details). The boxplot within each violin plot indicates the median and the interquartile range with the $95 \%$ confidence interval for the median. Surface prey included terrestrial arthropods and emerged aquatic insects

pelagic-littoral resource channels) in new scenarios promoted by environmental change, especially in LSR whitefish, as it switched from pelagic to benthic foraging in warmer and more productive lakes. This enhances the understanding that the relative competitive edge between these fish species shifts along a climate-productivity gradient. That is, in warmer and more productive lakes, whitefish are restricted to benthic habitats, likely due to the presence of pelagic specialist vendace and bleak (Hayden et al. 2017), while perch shows feeding specialisation but a more flexible habitat use (pelagic and benthic habitats, here demonstrated by stomach contents-Fig. 3). Such shifts are underlined by their relative contribution to lake fish community composition; whitefish dominate fish communities in cold and oligotrophic lakes, but warmer and more productive lakes are dominated by perch (Hayden et al. 2017; 2019).

We provided empirical support for the notion that prey availability can promote individual trophic specialisation of fish species, which triggers a concomitant rise in population niche breadth, along climate-productivity gradients. However, our results identify the key importance of prey abundance (rather than prey diversity) in driving individual and population feeding responses to new lentic scenarios driven by environmental change. Thus, biomass production in different trophic levels is likely to be key in understanding future changes in aquatic food web structure, where at high temperature and productivity tend to reduce invertebrate prey availability for fish consumers (Keva et al. 2021). It is reasonable to posit that feeding habits of animals, and thus individual trophic specialisation, can be limited either by low prey abundance or high consumer abundance (e.g. Araújo et al. 2011; Tinker et al. 2008; Costa-Pereira et al. 2017). Tinker et al. (2008) observed that foodlimiting environments (i.e. low prey resource abundance) drive increases in individual variation in sea otters. Likewise, Svanbäck et al. (2011) found that individual trophic specialisation of a benthic isopod is higher in scenarios with low prey abundance compared to scenarios with high prey abundance. In contrast, Barili et al. (2011) concluded that high diversity and abundance of food resources is associated with high degree of feeding specialisation of fish species, whereas generalisation in resource use may be independent of spatial heterogeneity in prey abundance (Sánchez-Hernández and Cobo 2013).

The current work partially supports previous studies (Tinker et al. 2008; Svanbäck et al. 2011), as individual trophic specialisation tends to decrease with increasing of prey abundance in generalist LSR whitefish and planktivore vendace (see Fig. 5). However, individual trophic specialisation of perch tends to increase with prey abundance (Cyclopoida and zooplankton total density). These seemingly contradictory standpoints highlight the capacity of multichannel consumers to display distinct behavioural feeding responses. The intuitive expectation is that competition for food should be higher when the number of consumers (i.e. per capita levels) are high, but also when food resources are scarce (Sánchez-Hernández et al. 2017b). However, within the extensive environmental gradient we studied, increasing prey resources are associated with very marked increases in the abundance of fish, suggesting strengthening of resource competition in more productive lakes (see Appendix 7 for further details), where thermal and visual performance are of key importance to succeed. Thus, in these situations, individuals may specialise on those abundant prey resources as predicted by optimal 


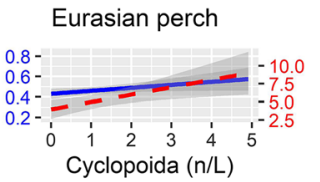

Ruffe

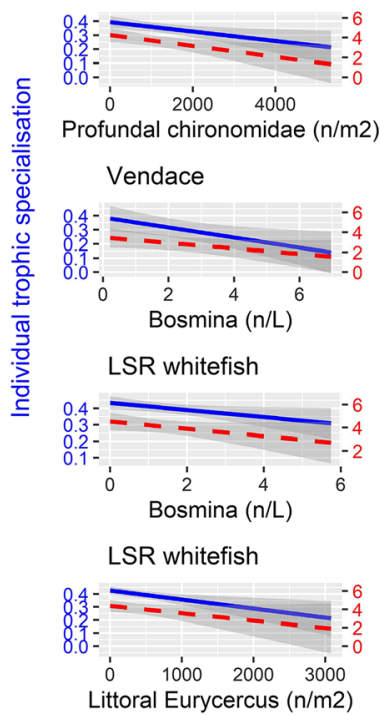

Eurasian perch

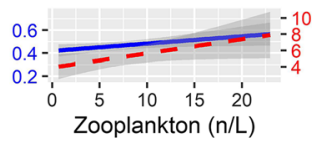

Ruffe

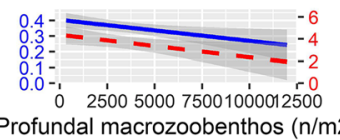

Profundal macrozoobenthos $(\mathrm{n} / \mathrm{m} 2)$

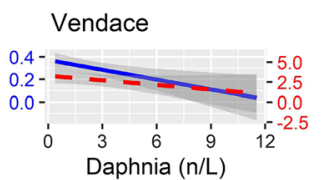

LSR whitefish

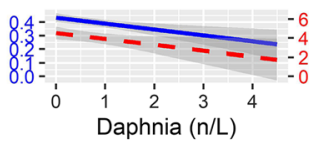

LSR whitefish

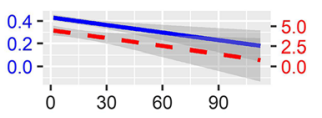

Total CPUE ( $\mathrm{n}$ net series- $1 \mathrm{~h}-1$ )
Eurasian perch

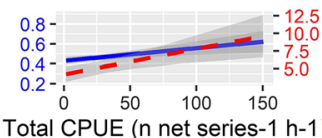

Total CPUE ( $\mathrm{n}$ net series- 1 h-1

$$
\text { Ruffe }
$$
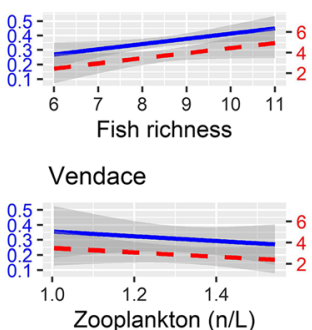

LSR whitefish

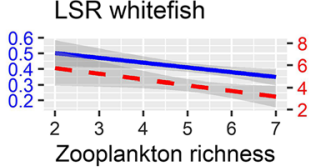

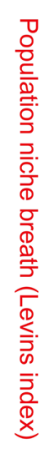

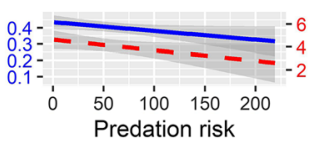

Fig. 5 Patterns in feeding responses (individual trophic specialisation and population niche breadth-Levins) along gradients of prey availability (macrozoobenthos and zooplankton densities) and fish community characteristics (CPUE, fish richness and predation risk). Linear smoothers (shaded area denotes $95 \%$ confidence interval) are fitted to the data for

foraging theory (MacArthur and Pianka 1966; Pyke et al. 1977) similar as seen for generalist perch (zooplankton abundance was an important driving force of individual trophic specialisation). From another standpoint, zooplankton could be a reliable proxy of pelagic habitat profitability for perch along a climate-productivity gradient. This reflects the fact that the species usually behaves as a littoral-benthic fish in northernmost lakes but use pelagic habitats more frequently in more southern lakes (Hayden et al. 2019)-however, the well reported benthic-pelagic foraging switch was not widely evident in the current study. While we only saw statistically significant responses in whitefish and perch in the current work, similar results may be evident in other generalist fish species such as brown trout, Arctic charr and roach if studied under a more extensive temperature and productivity gradient, representing an opening opportunity for future research. illustrative purposes of the patterns to show trends in feeding responses at population (solid blue line) and individual levels (dashed red line). Note panels only included the most relevant predictors of individual trophic specialisation and population niche breadth according to correlation analyses (see Appendix 5 for further details)

Factors other than environmental (warming and increased productivity) and prey availability, such as resource competition, may also be a major determinant of changes in individual and population-level trophic ecology in a changing world. Overall, the niche variation hypothesis predicts that populations tend to become more generalised when they are released from competition (Van Valen 1965). It is thought that the capacity of generalist fish to switch between pelagic and benthic resource channels (multichannel feeding) largely depends on inter- and intraspecific competition (Quevedo et al. 2009; Eloranta et al. 2013). Several studies support the notion that intraspecific resource competition promotes individual specialisation in fish species (e.g. Svanbäck and Persson 2004; Mendes et al. 2019), but there is also empirical support that fish species can display a generalist foraging behaviour independent of population density (Sánchez-Hernández and Cobo 2013). We demonstrated that interspecific competition, rather 
Table 2 Relative variable importance of the generalised additive models with substantial support according to model averaging $(\triangle \mathrm{AIC}<2)$. Total $\mathrm{CPUE}$ is considered here as a proxy of interspecific competition. The number of containing models $(n)$ are shown in brackets. The relative variable importance ranges from 0 to 1 , and thus 1 indicates that a variable was included in all models with substantial support. Most important variables are marked in bold. '-' removed during model selection

\begin{tabular}{|c|c|c|c|c|c|c|c|c|}
\hline & \multicolumn{4}{|c|}{ Individual trophic specialisation } & \multicolumn{4}{|c|}{ Levins' index } \\
\hline & $\begin{array}{l}\text { Eurasian } \\
\text { perch }\end{array}$ & Ruffe & Vendace & $\begin{array}{l}\text { LSR } \\
\text { whitefish }\end{array}$ & $\begin{array}{l}\text { Eurasian } \\
\text { perch }\end{array}$ & Ruffe & Vendace & $\begin{array}{l}\text { LSR } \\
\text { whitefish }\end{array}$ \\
\hline \multicolumn{9}{|l|}{ Predictor variables } \\
\hline Lake morphometry index $\left(M_{i}\right)$ & $0.62(31)$ & $0.09(2)$ & - & $0.43(15)$ & $0.74(8)$ & $0.07(1)$ & $0.04(1)$ & $0.09(3)$ \\
\hline Zooplankton richness & $0.11(7)$ & $0.13(2)$ & $0.27(1)$ & $0.17(7)$ & $0.33(3)$ & $0.11(2)$ & $0.42(9)$ & $0.34(10)$ \\
\hline Bosmina density $(\mathrm{n} / \mathrm{L})$ & $0.08(5)$ & $0.24(4)$ & - & $1.00(34)$ & $0.56(5)$ & $0.05(1)$ & $0.44(10)$ & $0.81(25)$ \\
\hline Daphnia density (n/L) & $0.76(39)$ & $0.05(1)$ & - & $0.06(3)$ & $0.75(9)$ & $0.05(1)$ & $0.18(4)$ & $0.28(10)$ \\
\hline Cyclopoida density (n/L) & $0.94(48)$ & - & - & $0.24(9)$ & $1.00(11)$ & - & - & $0.13(5)$ \\
\hline Total zooplankton density (n/L) & $0.25(13)$ & $0.26(4)$ & - & $0.53(18)$ & $0.44(6)$ & $0.05(1)$ & $0.28(6)$ & $0.12(5)$ \\
\hline Eurycercus density $\left(\mathrm{n} / \mathrm{m}^{2}\right)$ & $0.09(5)$ & $0.86(14)$ & - & $1.00(34)$ & $0.46(4)$ & $0.14(2)$ & - & $1.00(32)$ \\
\hline $\begin{array}{l}\text { Profundal Chironomidae density } \\
\left(\mathrm{n} / \mathrm{m}^{2}\right)\end{array}$ & $0.04(3)$ & $1.00(16)$ & - & $0.04(2)$ & $0.17(1)$ & $0.88(13)$ & - & $0.73(22)$ \\
\hline $\begin{array}{l}\text { Profundal macrozoobenthos density } \\
\left(\mathrm{n} / \mathrm{m}^{2}\right)\end{array}$ & $0.08(5)$ & $0.73(12)$ & - & $0.06(3)$ & $0.09(1)$ & $0.27(4)$ & - & $0.51(15)$ \\
\hline $\begin{array}{l}\text { Total CPUE (individuals net } \\
\text { series }^{-1} \mathrm{~h}^{-1} \text { ) }\end{array}$ & $0.92(47)$ & $0.10(2)$ & $0.23(1)$ & $1.00(34)$ & $0.83(10)$ & $0.11(2)$ & $0.30(7)$ & $1.00(32)$ \\
\hline Predation risk & $0.12(7)$ & $0.05(1)$ & - & $0.69(23)$ & - & $0.05(1)$ & $0.24(5)$ & $0.73(24)$ \\
\hline Fish richness & $0.15(9)$ & $0.10(2)$ & - & $0.28(10)$ & $0.48(5)$ & $0.06(1)$ & - & $1.00(32)$ \\
\hline \multicolumn{9}{|l|}{ Smooth terms } \\
\hline Climate-productivity index $\left(C P_{i}\right)$ & $0.61(31)$ & $1.00(16)$ & $1.00(3)$ & $1.00(34)$ & $0.55(6)$ & $0.17(3)$ & $0.07(2)$ & $1.00(32)$ \\
\hline
\end{tabular}

than intraspecific competition, emerged as a key variable in explaining individual trophic specialisation, and thus acting on population niche breadth, of lake-dwelling fish species. Our results highlight that interspecific competition promoted individual trophic specialisation in perch similar to previous works focused on intraspecific competition (Svanbäck and Persson 2004; Mendes et al. 2019), but that vendace and LSR whitefish became increasingly generalist under high-competition scenarios (higher fish abundances). There is limited niche space available for diminishing amounts of whitefish and vendace in warmer and more productive lakes, where they tend to be restricted to profundal and narrow pelagic habitats due to obvious resource competition with other species (Hayden et al. 2017). It should be kept in mind that there may be habitat squeeze in warming lakes driving sub-lethal stress (water temperature may limit fish growth through increased metabolic demand), which in turn, it is expected to affect population performance (e.g. Coutant 1985;
Lappalainen and Lehtonen 1997; Chadwick et al. 2015). We suggest that asymmetrical competition for food resources and multichannel feeding can drive more generalised feeding along climate-productivity gradients as observed in generalist cold-water adapted LSR whitefish, whereas competitively dominant fish species (here generalist cool-water adapted perch) can specialise in feeding towards warmer and more productive lakes. The observed distinct functional feeding responses of fish generalists along climateproductivity gradients underscores the importance of competitive interactions in fish assemblages in combination with prey availability, in aiding our understanding of shifts in feeding patterns at both individual and population levels along climate-productivity gradients.

We showed that the highest individual trophic specialisation of whitefish was seen in the coldest and least productive lakes included in our climate-productivity gradient, supporting hypothesis 2 . These patterns were only apparent in generalist LSR whitefish, 
Table 3 Summary table of the best model simulations (Generalised Additive Models) showing statistical information (estimate and significance) according to $\triangle \mathrm{AIC}$ values explaining the variation in individual trophic specialisation and population niche breadth (Levins' index) of fish species. Total CPUE used as a proxy of interspecific competition. Significance codes: '-' removed during model selection, $* * * 0.001$, $* * 0.01, * 0.05$

\begin{tabular}{lllllllll}
\multicolumn{2}{l}{ Individual trophic specialisation } & & & \multicolumn{2}{l}{ Levins' index } \\
\cline { 1 - 2 } $\begin{array}{l}\text { Eurasian } \\
\text { perch }\end{array}$ & Ruffe & Vendace & $\begin{array}{l}\text { LSR } \\
\text { whitefish }\end{array}$ & & $\begin{array}{l}\text { Eurasian } \\
\text { perch }\end{array}$ & Ruffe & Vendace & $\begin{array}{l}\text { LSR } \\
\text { whitefish }\end{array}$
\end{tabular}

\begin{tabular}{|c|c|c|c|c|c|c|c|c|}
\hline \multicolumn{9}{|l|}{ Parametric coefficients } \\
\hline Intercept & $0.420 * * *$ & $0.437 * * *$ & $0.305 * * *$ & $0.001 * * *$ & -4.199 & $4.264 * * *$ & $3.492 * * *$ & $10.981 * * *$ \\
\hline Bosmina density $(\mathrm{n} / \mathrm{L})$ & - & - & - & -0.013 & 0.271 & - & -0.275 & -0.243 \\
\hline Daphnia density $(\mathrm{n} / \mathrm{L})$ & -0.015 & - & - & - & $2.201 * *$ & - & - & - \\
\hline Cyclopoida density (n/L) & $0.030^{*}$ & - & - & - & - & - & - & - \\
\hline Zooplankton richness & - & - & - & - & -0.747 & - & - & - \\
\hline Eurycercus density $\left(\mathrm{n} / \mathrm{m}^{2}\right)$ & - & -0.001 & - & $-0.001 * * *$ & $-0.002 *$ & - & - & $-0.001 * * *$ \\
\hline $\begin{array}{l}\text { Profundal Chironomidae } \\
\text { density }\left(\mathrm{n} / \mathrm{m}^{2}\right)\end{array}$ & - & $-0.001^{*}$ & - & - & 0.001 & $-0.001 *$ & - & - \\
\hline $\begin{array}{l}\text { Profundal macrozoobenthos } \\
\text { density }\left(\mathrm{n} / \mathrm{m}^{2}\right)\end{array}$ & - & -0.001 & - & - & - & - & - & - \\
\hline $\begin{array}{l}\text { Total CPUE (individuals net } \\
\text { series }^{-1} \mathrm{~h}^{-1} \text { ) }\end{array}$ & 0.001 & - & - & $-0.008 * * *$ & - & - & - & $-0.182 * * *$ \\
\hline Predation risk & - & - & - & -0.001 & - & - & - & -0.009 \\
\hline Fish richness & - & - & - & -0.001 & 1.246 & - & - & $-0.376^{*}$ \\
\hline Lake morphometry index $\left(M_{i}\right)$ & - & - & - & - & $1.183^{*}$ & - & - & - \\
\hline \multicolumn{9}{|l|}{ Smooth terms } \\
\hline $\begin{array}{l}\text { Climate-productivity index } \\
\left(C P_{i}\right)\end{array}$ & 1.00 & 2.774 & $3.800 *$ & $3.450 *$ & $3.81^{*}$ & - & - & $3.628 * *$ \\
\hline \multicolumn{9}{|l|}{ Model statistics } \\
\hline$n$ & 21 & 16 & 12 & 29 & 21 & 16 & 12 & 29 \\
\hline $\mathrm{R}^{2}$ & 0.48 & 0.60 & 0.71 & 0.67 & 0.71 & 0.30 & 0.20 & 0.61 \\
\hline Deviance explained (\%) & 58.1 & 75.2 & 80.9 & 77.1 & 86.5 & 35 & 27.5 & 73.3 \\
\hline
\end{tabular}

considered the ancestral form of this widely distributed and ecologically plastic fish (Harrod et al. 2010; Siwertsson et al. 2010; Häkli et al. 2018). No statistically significant trends were observed in the derived specialist whitefish morphs i.e. DR, SSR and LDR whitefish. This is not surprising, as specialist morphs are present only in cold oligotrophic lakes, where resource polymorphism of whitefish is most common (Harrod et al. 2010; Häkli et al. 2018). In warmer and more productive environments, competitors such as vendace and perch likely outperform the specialised whitefish morphs, and whitefish occur only in the monomorphic generalist LSR. A collapse to single morph may include speciation reversal due to hybridisation with other morphs or vendace (Kahilainen et al. 2011; Vonlanthen et al. 2012; Bhat et al.
2014). Whitefish divergence requires elevated levels of prey availability and competitor exclusion that often derives from historical contingency in species recolonization of postglacial landscapes (Bøhn et al. 2008; Siwertsson et al. 2010; Skúlason et al. 2019). Thus, species-specific optimal thermal and productivity conditions are required for individual trophic specialisation to occur to a point that could be followed by divergence into sympatric morphs. At a larger scale, this may suggest that perch is prone to diverge in warmer and mesotrophic lakes [e.g. Sweden (Svanback and Eklov 2003)] and Arctic charr in colder conditions [Norway (Skoglund et al. 2015)] than those examined here. This highlights a need for future studies of resource polymorphism to (1) consider climate-productivity landscapes across wider 
geographic and environmental scales and (2) realise that these gradients likely extend well beyond political boundaries.

In conclusion, we demonstrate how environmental change drives taxa-specific behavioural feeding responses at population and individual levels of fish species. Our findings underscore the importance of species-specific feeding plasticity, and thus their capacity to display foraging switches along the littoral-pelagic axis (multichannel feeding) to cope with increased thermal stress and pelagic productivity as a result of climate change. It is reasonable to posit that fish species display distinct behavioural responses to adapt to new abiotic (warming and productivity) and biotic (poleward shifts of fish assemblages, competitive interactions and changes in prey communities) conditions pending on their thermal guild and visual capacity. At a subspecies level, warmer conditions are likely to lead to the extinction of coldadapted specialised morphs in some locations. Conversely, it is likely that we will see more intraspecific morphs formed in more warm-adapted species. Overall, future climate change scenarios are likely to provide an advantage to widely distributed generalist fish species capable of switching between foraging strategies to cope with changing competitive interactions and food resources as response of climate change.

Acknowledgements We thank numerous students, colleagues and research station staff for their help. Specifically, we are grateful to Kilpisjärvi Biological Station, Muddusjärvi Research Station, Kevo Subarctic Research Institute, Muonio County Fish Facility, Nuottavaara Village Association for their research facilities. Research was funded by numerous sources including Academy of Finland (Projects 1140903, 1268566 to KKK) European Regional Development Fund (A30205 to KKK), Ministry of Agriculture and Forestry (KKK), Inari Municipality (KKK), Biological Interactions Graduate School (KKK) and Grants from Finnish foundations (KKK). $\mathrm{CH}$ is supported by Nucleo Milenio INVASAL funded by the ANID-Millennium Science Initiative-NCN16_034. At all stages of this study, national guidelines (FI-564/2013 and FI-487/2013) and the European Union directive (2010/63/EU) on the protection of animals used for scientific purposes were applied. We also appreciate constructive comments from two anonymous reviewers, which considerably improved the quality of the manuscript.

Open Access This article is licensed under a Creative Commons Attribution 4.0 International License, which permits use, sharing, adaptation, distribution and reproduction in any medium or format, as long as you give appropriate credit to the original author(s) and the source, provide a link to the Creative
Commons licence, and indicate if changes were made. The images or other third party material in this article are included in the article's Creative Commons licence, unless indicated otherwise in a credit line to the material. If material is not included in the article's Creative Commons licence and your intended use is not permitted by statutory regulation or exceeds the permitted use, you will need to obtain permission directly from the copyright holder. To view a copy of this licence, visit http://creativecommons.org/licenses/by/4.0/.

Authors contribution All authors made substantial intellectual contribution to this work. KKK, $\mathrm{BH}$ and $\mathrm{CH}$ designed the study; JSH conducted data analysis and led the writing. All authors discussed the results and contributed to writing and editing the manuscript.

Funding Open Access funding provided thanks to the CRUECSIC agreement with Springer Nature.

Data availability Data available from the Figshare Digital Repository (https://doi.org/10.6084/m9.figshare.16437837).

\section{References}

Amundsen P-A, Sánchez-Hernández J (2019) Feeding studies take guts: critical review and recommendations of methods for stomach contents analysis in fish. J Fish Biol 95:1364-1373

Araújo MS, Bolnick DI, Layman CA (2011) The ecological causes of individual specialisation. Ecol Lett 14:948-958

Barili E, Agostinho AA, Gomes LC, Latin JD (2011) The coexistence of fish species in streams: relationships between assemblage attributes and trophic and environmental variables. Environ Biol Fishes 92:41-52

Bartley TJ, McCann KS, Bieg C et al (2019) Food web rewiring in a changing world. Nat Ecol Evol 3:345-354

Bartoń K (2016) MuMIn: multi-model inference. R package version 1.15.6. Available at: https://CRAN.R-project.org/ package $=$ MuMIn. Last accessed August 2021

Beitinger TL, Bennett WA, McCauley RW (2000) Temperature tolerances of North American freshwater fishes exposed to dynamic changes in temperature. Environ Biol Fishes 58:237-275

Bestion E, Soriano-Redondo A, Cucherousset J et al (2019) Altered trophic interactions in warming climates: consequences for predator diet breadth and fitness. Proc R Soc Lond B 286:20192227

Bhat S, Amundsen P-A, Knudsen R, Gjelland KØ, Fevolden S-E, Bernatchez L, Præbel K (2014) Speciation reversal in european whitefish (Coregonus lavaretus L.) caused by competitor invasion. PLoS ONE 9:e91208

Bhowmik AK, Schäfer RB (2015) Large scale relationship between aquatic insect traits and climate. PLoS ONE 10:e0130025

Bøhn T, Amundsen P-A, Sparrow A (2008) Competitive exclusion after invasion? Biol Invasions 10:359-436 
Bolnick DI, Yang LH, Fordyce JA, Davis JM, Svanbäck R (2002) Measuring individual-level resource specialization. Ecology 83:2936-2941

Burnham KP, Anderson DR (2002) Model selection and multimodel inference: a practical information-theoretical approach, 2nd edn. Springer, New York

Chadwick JG, Nislow KH, McCormick SD (2015) Thermal onset of cellular and endocrine stress responses correspond to ecological limits in brook trout, an iconic cold-water fish. Conserv Physiol 3:1-12

Comte L, Grenouillet G (2013) Do stream fish track climate change? Assessing distribution shifts in recent decades. Ecography 36:1236-1246

Costa-Pereira R, Tavares LER, Camargo PB, Araújo MS (2017) Seasonal population and individual niche dynamics in a tetra fish in the Pantanal wetlands. Biotropica 49:531-538

Coumou D, Di Capua G, Vavrus S, Wang L, Wang S (2018) The influence of Arctic amplification on mid-latitude summer circulation. Nat Commun 9:2959

Coutant CC (1985) Striped bass, temperature and dissolved oxygen: a speculative hypothesis for environmental risk. Trans Am Fish Soc 114:31-61

Daufresne M, Roger MC, Capra H, Lamouroux N (2003) Longterm changes within the invertebrate and fish communities of the Upper Rhône River: effects of climatic factors. Glob Chang Biol 10:124-140

Daufresne M, Lengfellner K, Sommer U (2009) Global warming benefits the small in aquatic ecosystems. Proc Natl Acad Sci USA 106:12788-12793

de Senerpont Domis LN, Elser JJ, Gsell AS et al (2013) Plankton dynamics under different climatic conditions in space and time. Freshw Biol 58:463-482

Duffy JE, Cardinale BJ, France KE, McIntyre PB, Thébault E, Loreau M (2007) The functional role of biodiversity in ecosystems: incorporating trophic complexity. Ecol Lett 10:522-538

Eloranta AP, Knudsen R, Amundsen P-A (2013) Niche segregation of coexisting Arctic charr (Salvelinus alpinus) and brown trout (Salmo trutta) constrains food web coupling in subarctic lakes. Freshw Biol 58:207-221

Encina L, Rodríguez-Ruiz A, Granado-Lorencio C (2004) Trophic habits of the fish assemblage in an artificial freshwater ecosystem: the Joaquin Costa reservoir, Spain. Folia Zool 53:437-449

Finstad AG, Andersen T, Larsen S, Tominage K, Blumentrath S, de Wit HA, Tømmervik H, Hessen DO (2016) From greening to browning: catchment vegetation development and reduced S-deposition promote organic carbon load on decadal time scales in Nordic lakes. Sci Rep 6:31944

Garcia-Palacios P, Vandegehuchte ML, Shaw EA, Dam M, Post KH, Ramirez KS, Sylvain ZA, de Tomasel CM, Wall DH (2015) Are there links between responses of soil microbes and ecosystem functioning to elevated $\mathrm{CO}_{2}, \mathrm{~N}$ deposition and warming? A global perspective. Glob Chang Biol 21:1590-1600

Gerking SD (1994) Feeding ecology of fish. Academic Press, San Diego

Graham CT, Harrod C (2009) Implications of climate change for the fishes of the British Isles. J Fish Biol 74:1143-1205

Häkli K, Østbye K, Kahilainen KK, Amundsen P-A, Præbel K (2018) Diversifying selection drives parallel evolution of gill raker number and body size along the speciation continuum of European whitefish. Ecol Evol 8:2617-2631

Hampton SE, Izmesteva LR, Moore MV, Dennis B, Silow EA (2008) Sixty years of environmental change in the world's largest lake: Lake Baikal, Siberia. Glob Chang Biol 14:1947-1958

Harrod C, Mallela J, Kahilainen KK (2010) Phenotype-environment correlations in a putative whitefish adaptive radiation. J Anim Ecol 79:1057-1068

Hayden B, Harrod C, Kahilainen KK (2014) Lake morphometry and resource polymorphism determine niche segregation between cool and cold-water adapted fish. Ecology 95:538-552

Hayden B, Myllykangas J-P, Rolls RJ, Kahilainen KK (2017) Climate and productivity shape fish and invertebrate community structure in subarctic lakes. Freshw Biol 62:990-1003

Hayden B, Harrod C, Thomas SM et al (2019) From clear lakes to murky waters: tracing the functional response of highlatitude lake communities to concurrent 'greening' and 'browning.' Ecol Lett 22:807-816

Hynes HBN (1950) The food of fresh-water sticklebacks (Gasterosteus aculeatus and Pygosteus pungitius), with a review of methods used in studies of the food of fishes. J Anim Ecol 19:36-58

Jacobson PC, Stefan HG, Pereira DL (2010) Coldwater fish oxythermal habitat in Minnesota lakes: influence of total phosphorus, July air temperature, and relative depth. Can J Fish Aquat Sci 67:2002-2013

Jacobson PC, Hansen GJA, Bethke BJ, Cross TK (2017) Disentangling the effects of a century of eutrophication and climate warming on freshwater lake fish assemblages. PLoS ONE 12:e0182667

Jeppesen E, Mehner T, Winfield IJ et al (2012) Impacts of climate warming on the long-term dynamics of key fish species in 24 European lakes. Hydrobiologia 694:1-39

Kahilainen KK, Ostbye K, Harrod C, Shikano T, Malinen T, Merilä J (2011) Species introduction promotes hybridization and introgression in Coregonus: is there sign of selection against hybrids? Mol Ecol 20:3838-3855

Kahilainen KK, Patterson WP, Sonninen E, Harrod C, Kiljunen M (2014) Adaptive radiation along a thermal gradient: Preliminary results of habitat use and respiration rate divergence among whitefish morphs. PLoS ONE 9:e112085

Kahilainen KK, Thomas SM, Nystedt EKM, Keva O, Malinen T, Hayden B (2017) Ecomorphological divergence drives differential mercury bioaccumulation in polymorphic European whitefish (Coregonus lavaretus) populations of subarctic lakes. Sci Total Environ 599-600:1768-1778

Keva O, Taipale SJ, Hayden B, Thomas SM, Vesterinen J, Kankaala P, Kahilainen KK (2021) Increasing temperature and productivity change biomass, trophic pyramids and community level omega-3 fatty acid content in subarctic lake food webs. Glob Chang Biol 27:282-296

Kingsbury KM, Gillanders BM, Booth DJ, Nagelkerken I (2020) Trophic niche segregation allows range-extending coral reef fishes to co-exist with temperate species under climate change. Glob Chang Biol 26:721-733 
Kottelat M, Freyhof J (2007) Handbook of European Freshwater Fishes. Kottelat, Cornol, Switzerland and Freyhof, Berlin, Germany

Kritzberg ES, Hasselquist EM, Škerlep M, Löfgren S, Olsson O, Stadmark J, Laudon H (2020) Browning of freshwaters: consequences to ecosystem services, underlying drivers, and potential mitigation measures. Ambio 9:375-390

Lappalainen J, Lehtonen H (1997) Temperature habitats for freshwater fishes in a warming climate. Boreal Environ Res 2:69-84

Levins R (1968) Evolution in changing environments: some theoretical explorations. Princeton University Press, New Jersey

Li F, Kwon Y-S, Bae M-J, Chung N, Kwon T-S, Park Y-S (2014) Potential impacts of global warming on the diversity and distribution of stream insects in South Korea. Conserv Biol 28:498-508

Liem KF (1980) Adaptive significance of intra- and interspecific differences in the feeding repertoires of cichlid fishes. Am Zool 20:295-314

MacArthur RH, Pianka ER (1966) On optimal use of a patchy environment. Am Nat 100:603-609

Magnuson JJ, Crowder LB, Medwick PA (1979) Temperature as an ecological resource. Am Zool 19:331-343

Matthews WJ, Maness JD (1979) Critical thermal maxima, oxygen tolerances and success of cyprinid fishes in a Southwestern river. Am Midl Nat 102:374-377

Matulla C, Schmutz S, Melcher A, Gerersdorfer T, Haas P (2007) Assessing the impact of a downscaled climate change simulation on the fish fauna in an Inner-Alpine River. Int J Biometeorol 52:127-137

Mehner T, Keeling C, Emmrich M et al (2016) Effects of fish predation on density and size spectra of prey fish communities in lakes. Can J Fish Aquat Sci 73:506-518

Mendes A, Fernandes IM, Penha J, Mateus L (2019) Intra and not interspecific competition drives intra-populational variation in resource use by a neotropical fish species. Environ Biol Fishes 102:1097-1110

Mirabasso J, Bissattini AM, Bologna MA, Luiselli L, Stellati L, Vignoli L (2020) Feeding strategies of co-occurring newt species across different conditions of syntopy: a test of the "within-population niche variation" hypothesis. Diversity 12:181

Moss B, Hering D, Green AJ et al (2009) Climate change and the future of freshwater biodiversity in Europe: a primer for policy makers. Freshw Rev 2:103-130

Nilsson PA, Jacobsen L, Berg S, Skov C (2009) Environmental conditions and intraspecific interference: unexpected effects of turbidity on pike (Esox lucius) foraging. Ethology $115: 33-38$

Pecuchet L, Blanchet M-A, Frainer A, Husson B, Jørgensen LL, Kortsch S, Primicerio R (2020) Novel feeding interactions amplify the impact of species redistribution on an Arctic food web. Glob Chang Biol 26:4894-4906

Persson L (1986) Effects of reduced interspecific competition on resource utilization in perch (Perca fluviatilis). Ecology 67:355-364

Persson L (1990) Juvenile competitive bottlenecks: the perch (Perca fluviatilis)-roach (Rutilus rutilus) interaction. Ecology 71:44-56
Præbel K, Knudsen R, Siwertsson A, Karhunen M, Kahilainen KK, Ovaskainen O, Amundsen P-A (2013) Ecological speciation in postglacial European whitefish: rapid adaptive radiations into the littoral, pelagic, and profundal lake habitats. Ecol Evol 3:4970-4986

Pyke GH, Pulliam HR, Charnov EL (1977) Optimal foraging: a selective review of theory and tests. Q Rev Biol 52:137-154

Quevedo M, Svanbäck R, Eklöv P (2009) Intrapopulation niche partitioning in a generalist predator limits food web connectivity. Ecology 90:2263-2274

R Core Team (2019) R: a language and environment for statistical computing. R Foundation for Statistical Computing, Vienna, Austria. Available at: https://www.R-project. org/. Last accessed August 2021

Rijnsdorp AD, Peck MA, Engelhard GH, Möllmann C, Pinnegar JK (2009) Resolving the effect of climate change on fish populations. ICES J Mar Sci 66:1570-1583

Robinson BW, Wilson DS (1998) Optimal foraging, specialization, and a solution to Liem's paradox. Am Nat 151:223-235

Rolls RJ, Hayden B, Kahilainen KK (2017) Conceptualising the interactive effects of climate change and biological invasions on subarctic freshwater fish. Ecol Evol 7:4109-4128

Sánchez-Hernández J, Cobo F (2013) Foraging behaviour of brown trout in wild populations: can population density cause behaviorally-mediated foraging specializations? Anim Biol 63:425-450

Sánchez-Hernández J, Vieira-Lanero R, Servia MJ, Cobo F (2011) Feeding habits of four sympatric fish species in the Iberian Peninsula: keys to understanding coexistence using prey trais. Hydrobiologia 667:119-132

Sánchez-Hernández J, Eloranta AP, Finstad AG, Amundsen P-A (2017a) Community structure affects trophic ontogeny in a predatory fish. Ecol Evol 7:358-367

Sánchez-Hernández J, Glaber H-M, Amundsen P-A (2017b) Prey diversity as a driver of resource partitioning between river-dwelling fish species. Ecol Evol 7:2058-2068

Sánchez-Hernández J, Finstad AG, Arnekleiv JV, Kjærstad G, Amundsen P-A (2019a) Drivers of diet patterns in a globally distributed freshwater fish species. Can J Fish Aquat Sci 76:1263-1274

Sánchez-Hernández J, Nunn AD, Adams C, Amundsen P-A (2019b) Causes and consequences of ontogenetic dietary shifts: a global synthesis using fish models. Biol Rev 94:539-554

Sánchez-Hernández J, Finstad AG, Arnekleiv JV, Kjærstad G, Amundsen P-A (2021) Beyond ecological opportunity: prey diversity rather than abundance shapes predator niche variation. Freshw Biol 66:44-61

Schluter D (2000) The ecology of adaptive radiation. Oxford University Press, Oxford

Siwertsson A, Knudsen R, Kahilainen KK, Præbel K, Primicerio R, Amundsen P-A (2010) Sympatric diversification as influenced by ecological opportunity and historical contingency in a young species lineage of whitefish. Evol Ecol Res 12:929-947

Skoglund S, Siwertsson A, Amundsen P-A, Knudsen R (2015) Morphological divergence between three Arctic charr morphs-the significance of the deep-water environment. Ecol Evol 5:3114-3129 
Skúlason S, Parsons K, Svanbäck R et al (2019) A way forward with eco evo devo: an extended theory of resource polymorphism with postglacial fishes as model systems. Biol Rev 94:1786-1808

Svanbäck R, Persson L (2004) Individual diet specialisation, niche width and population dynamics: implications for trophic polymorphisms. J Anim Ecol 73:973-982

Svanbäck R, Rydberg C, Leonardsson K, Englund G (2011) Diet specialisation in a fluctuating population of Saduria entomon: a consequence of resource or forager densities? Oikos 120:848-854

Tanentzap AJ, Morabito G, Volta P, Rogora M, Yan ND, Manca M (2020) Climate warming restructures an aquatic food web over 28 years. Glob Chang Biol 26:6852-6866

Thomas SM, Harrod C, Hayden B, Malinen T, Kahilainen KK (2017) Ecological speciation in a generalist consumer expands the trophic niche of a dominant predator. Sci Rep 7:8765

Till A, Rypel AL, Bray A, Fey SB (2019) Fish die-offs are concurrent with thermal extremes in north temperate lakes. Nat Clim Change 9:637-641

Tinker MT, Bentall G, Estes JA (2008) Food limitation leads to behavioral diversification and dietary specialisation in sea otters. PNAS 105:560-565

Van Valen L (1965) Morphological variation and width of ecological niche. Am Nat 99:377-390

Vonlanthen P, Bittner D, Hudson AG et al (2012) Eutrophication causes speciation reversal in whitefish adaptive radiations. Nature 482:357-362
Whitney JE, Al-Chokhachy R, Bunnell DB, Caldwell CA, Cooke SJ, Eliason JEJ, Rogers M, Lynch AJ, Paukert CP (2016) Physiological basis of climate change impacts on North American inland fishes. Fisheries 41:332-345

Wolkovich EM, Allesina S, Cottingham KL, Moore JC, Sandin SA, de Mazancourt C (2014) Linking the green and brown worlds: the prevalence and effect of multichannel feeding in food webs. Ecology 95:3376-3386

Wood SN (2017) Generalized additive models: an introduction with R. CRC Press, Boca Raton

Xenopoulos MA (2019) Editorial: long-term studies in limnology and oceanography. Limnol Oceanogr 64:S1

Zaccarelli N, Bolnick DI, Mancinelli G (2013) RInSp: an r package for the analysis of individual specialization in resource use. Methods Ecol Evol 4:1018-1023

Zuur AF, Ieno EN, Walker NJ, Saveliev AA, Smith GM (2009) Mixed effects models and extensions in ecology with R. Springer, New York

Zuur AF, Ieno EN, Elphick CS (2010) A protocol for data exploration to avoid common statistical problems. Methods Ecol Evol 1:3-14

Publisher's Note Springer Nature remains neutral with regard to jurisdictional claims in published maps and institutional affiliations. 